\title{
A phase 3, long-term, open-label safety study of Galcanezumab in patients with migraine
}

Angelo Camporeale ${ }^{1}$, David Kudrow ${ }^{2,3}$, Ryan Sides ${ }^{4}$, Shufang Wang ${ }^{4}$, Annelies Van Dycke ${ }^{5}$, Katherine J. Selzler ${ }^{4}$ and Virginia L. Stauffer ${ }^{4^{*}}$

\begin{abstract}
Background: Galcanezumab, a humanized monoclonal antibody that selectively binds to the calcitonin generelated peptide, has demonstrated in previous Phase 2 and Phase 3 clinical studies ( $\leq 6$-month of treatment) a reduction in the number of migraine headache days and improved patients' functioning. This study evaluated the safety and tolerability, as well as the effectiveness of galcanezumab for up to 12 months of treatment in patients with migraine.
\end{abstract}

Methods: Patients diagnosed with episodic or chronic migraine, 18 to 65 years old, that were not exposed previously to galcanezumab, were randomized to receive galcanezumab $120 \mathrm{mg}$ or $240 \mathrm{mg}$, administered subcutaneously once monthly for a year. Safety and tolerability were evaluated by frequency of treatmentemergent adverse events (TEAEs), serious adverse events (SAEs), and adverse events (AEs) leading to study discontinuation. Laboratory values, vital signs, electrocardiograms, and suicidality were also analyzed. Additionally, overall change from baseline in the number of monthly migraine headache days, functioning, and disability were assessed.

Results: One hundred thirty five patients were randomized to each galcanezumab dose group. The majority of patients were female (> 80\%) and on average were 42 years old with 10.6 migraine headache days per month at baseline. $77.8 \%$ of the patients completed the open-label treatment phase, 3.7\% of patients experienced an SAE, and $4.8 \%$ discontinued due to AEs. TEAEs with a frequency $\geq 10 \%$ of patients in either dose group were injection site pain, nasopharyngitis, upper respiratory tract infection, injection site reaction, back pain, and sinusitis. Laboratory values, vital signs, or electrocardiograms did not show anyclinically meaningful differences between galcanezumab dosesOverall mean reduction in monthly migraine headache days over 12 months for the galcanezumab dose groups were $5.6(120 \mathrm{mg})$ and $6.5(240 \mathrm{mg})$. Level of functioning was improved and headacherelated disability was reduced in both dose groups.

Conclusion: Twelve months of treatment with self-administered injections of galcanezumab was safe and associated with a reduction in the number of monthly migraine headache days. Safety and tolerability of the 2 galcanezumab dosing regimens were comparable.

Trial registration: ClinicalTrials.gov as NCT02614287, posted November 15, 2015. These data were previously presented as a poster at the International Headache Congress 2017: PO-01-184, Late-Breaking Abstracts of the 2017 International Headache Congress. (2017). Cephalalgia, 37(1_suppl), 319-374.

Keywords: Migraine, Headache, Galcanezumab, CGRP

\footnotetext{
* Correspondence: vstauffer@lilly.com

${ }^{4}$ Eli Lilly and Company Corporate Center, Indianapolis, IN 46285, USA

Full list of author information is available at the end of the article
}

(c) The Author(s). 2018 Open Access This article is distributed under the terms of the Creative Commons Attribution 4.0 International License (http://creativecommons.org/licenses/by/4.0/), which permits unrestricted use, distribution, and reproduction in any medium, provided you give appropriate credit to the original author(s) and the source, provide a link to the Creative Commons license, and indicate if changes were made. The Creative Commons Public Domain Dedication waiver (http://creativecommons.org/publicdomain/zero/1.0/) applies to the data made available in this article, unless otherwise stated. 


\section{Background}

In the 2015 Global Burden of Disease study, migraine was reported to be 1 of 8 chronic diseases affecting more than $10 \%$ of the world population [1], with higher prevalence among women (17\%) than men (6\%) [2]. Patients with migraine also have higher lifetime rates of depression, anxiety, panic disorder, sleep disturbances, chronic pain syndromes, musculoskeletal symptoms, ischemic stroke (migraine with aura), and suicide attempts [3-9]. Despite its prevalence, migraine continues to be underdiagnosed and undertreated.

Migraine-specific medications, such as triptans and ergotamines, as well as nonsteroidal anti-inflammatory drugs, are taken acutely to abort the migraine attack. However, for patients with frequent migraine attacks, and for whom abortive treatments are inadequately effective, preventive therapies are recommended [10-12]. It is estimated that approximately $39 \%$ of migraine patients would benefit from preventive pharmacotherapy to reduce the frequency of migraine attacks [2], which includes the ability to function at work and school, and interferes with family and social interactions [13].

For patients with chronic migraine, there are two preventive treatments considered as standard of care, onabotulinumtoxinA and topiramate, which are the most frequently prescribed medications for chronic migraine $[14,15]$. In the US and Europe the use of beta blockers, calcium channel blockers, anticonvulsants, nonsteroidal anti-inflammatory drugs, and antidepressants as migraine preventive medications are proposed [10, 16, 17]. Although all of these medications are considered preventive treatment for episodic or chronic migraine, none of them were developed specifically to treat migraine, and some are not well tolerated [18].

During migraine attacks, serum concentrations of calcitonin gene-related peptide (CGRP) are significantly elevated in the external jugular vein $[19,20]$, implicating CGRP in the pathophysiology of migraine. Galcanezumab is a humanized monoclonal antibody that potently and selectively binds to CGRP without blocking the receptor, preventing CGRP-mediated biological effects [21]. In two 12-week Phase 2 [22, 23] and two 6-month Phase 3 [24] clinical studies of patients with episodic migraine, galcanezumab significantly reduced monthly migraine headache days (MHD) compared to placebo. The purpose of this study was to investigate the long-term safety, tolerability, and effectiveness of galcanezumab treatment in patients with migraine.

\section{Methods}

This study was a Phase 3, multicenter, randomized, long-term, open-label study to assess the safety of two dosing regimens of galcanezumab, $120 \mathrm{mg} / \mathrm{month}$ (with initial loading dose of $240 \mathrm{mg}$ ) and $240 \mathrm{mg} / \mathrm{month}$, for the treatment of episodic or chronic migraine. The study protocol was reviewed and approved by appropriate institutional review boards and was conducted according to Good Clinical Practice and the Declaration of Helsinki. Patients provided written informed consent before initiating study procedures. Enrollment began in December 2015 and the last patient completed the study (treatment phase and post-treatment phase) in September 2017. There were 28 clinical sites across 5 countries (United States, Canada, Hungary, Belgium, and France) that participated in the study.

\section{Patient selection}

Eligibility for study enrollment was based on the results of migraine history, physical examination, neurological examination, clinical laboratory tests and electrocardiograms (ECGs). Key inclusion criteria were: 18-65 years of age; diagnosis of migraine as defined by the International Headache Society (IHS) International Classification of Headache Disorders (ICHD)-3 beta version [25] a history of at least 1 year of migraine headaches; migraine onset prior to age 50 years; prior to study entry, a history of 4 or more MHD per month on average for the past 3 months and a history of at least 1 headache-free day per month for the past 3 months. Key exclusion criteria were: prior exposure to galcanezumab (or any other CGRP antibody); use of any therapeutic antibody in the past 12 months; current treatment with preventive migraine medication; history of failure to respond to three or more classes of migraine preventive treatments (as defined by the American Academy of Neurology treatment guidelines Level A or Level B evidence [16]); presence of a medical condition that would preclude study participation, including pregnancy, presence of suicidal ideation within the past month, history of substance abuse or dependence in the past year, or recent history of acute cardiovascular events and/or serious cardiovascular risk based on history or ECG findings. Patients were allowed to take acute medications (except opiod and barbituates more than three times per month) for the treatment of migraine during the study, including triptans, ergots, nonsteroidal anti-inflammatory drugs and acetaminophen.

\section{Objectives}

The primary objective was to evaluate the long-term safety and tolerability of galcanezumab (120 and $240 \mathrm{mg} / \mathrm{month}$ ) for up to 1 year of treatment. Assessments included serious adverse events (SAEs), treatment-emergent adverse events (TEAEs), discontinuation rates, vital signs and weight, ECGs, laboratory measures, suicidal ideation and behavior using the Columbia Suicide Severity Rating Scale (C-SSRS) [26], and incidence of treatment-emergent anti-drug antibodies (TE-ADA). 
Secondary objectives included the evaluation of efficacy measures to fully assess the longer-term effectiveness of galcanezumab in the prevention of migraine. The evaluation included overall change from baseline in the number of monthly MHD, headache days, responder analysis of $\geq 30 \%, \geq 50 \%, \geq 75$, and $100 \%$ reduction in MHD, the percentage of patients who maintained a monthly MHD response, and change from baseline in the number of days acute treatment is taken for migraine or headache. Additional efficacy measures included patient-rated impression of illness improvement, change from baseline in functioning assessed by the Migraine-Specific Quality of Life questionnaire (MSQ) [27] and change from baseline in headache-related disability assessed by the Migraine Disability Assessment (MIDAS) scale [28, 29].

The number of MHD and headache days were reported by patients for the month prior to the study visit. Response rates were based on the reduction in number of MHD reported monthly and overall. Maintenance of response was a post-hoc assessment of patients meeting $\geq 50 \%$ response at any month and subsequently maintaining $\geq 40 \%$ response for at least two months or until the patient's endpoint. This maintenance of response could range from $\geq 3$ months to 12 consecutive months (including initial month of response).

\section{Clinical assessments}

The C-SSRS evaluates the occurrence, severity, and frequency of suicide-related thoughts and behaviors during the assessment period. The scale includes suggested questions to solicit the type of information needed to determine if a suicide-related thought or behavior occurred [26].

The Patient Global Impression of Improvement (PGI-I) scale [30] is a patient-rated instrument that measures the improvement of the patient's symptoms. It is a 7-point scale in which a score of 1 indicates that the patient is "very much better," a score of 4 indicates that the patient has experienced "no change," and a score of 7 indicates that the patient is "very much worse."

The MSQ (v2.1) is a self-administered health status instrument that was developed to address physical and emotional limitations of specific concern to individuals suffering from migraine headaches. The instrument consists of 14 items that addresses 3 domains: (1) Role Function-Restrictive (RF-R), (2) Role Function-Preventive, and (3) Emotional Function [27]. The instrument was designed with a 4-week recall period and is considered reliable, valid, and sensitive to change in migraine $[27,31]$ with a 0 to 100 scale, with higher scores indicating a better health status.

The MIDAS was designed to quantify headache-related disability, recalled over a 3-month period. This instrument consists of five items that reflect the number of days reported as missing or with reduced productivity at work, home, or social events. The items are weighted in the final scores, with a higher value indicating greater disability $[28,29]$. This instrument is considered highly reliable, valid, and is correlated with clinical judgment regarding the need for medical care $[28,29]$.

\section{Study design}

The study was comprised of 3 study periods. Study Period 1 included initial screening procedures and washout of all migraine preventive treatments (3-45 days). In Study Period 2 (open-label treatment period), patients were randomized to treatment with one of two dosing regimens of galcanezumab $(120 \mathrm{mg}$ or $240 \mathrm{mg})$ that were administered subcutaneously once monthly for a total of 12 doses. Patients randomized to galcanezumab $120 \mathrm{mg}$ received an initial loading dose of $240 \mathrm{mg}$ (two injections of $120 \mathrm{mg}$ each), and all subsequent doses were self- or caregiver-administered as a single injection of $120 \mathrm{mg}$ monthly. Those randomized to galcanezumab $240 \mathrm{mg}$ received two injections of $120 \mathrm{mg}$ at each monthly dosing visit. Across the study, there were office visits at Months 1-3, 6, 9, and 12; Months 4, 5, 7, 8, 10, and 11 were telephone visits. Injections were delivered by prefilled syringe or by an investigational autoinjector. Each patient or caregiver received training on the use of the prefilled syringe and autoinjector. Patients were to keep track of their headaches, both migraine and non-migraine, experienced in the past 30 days, as well as the use of medication taken for the acute treatment of a migraine and non-migraine headache. Patients were required to report a migraine headache, headache or use of an acute medication for migraine or headache on a daily basis with a diary or log of their choice, and the daily $\log$ was reviewed at each monthly visit and documented in the case report form. Study Period 3 was a 4-month post-treatment period (washout phase), during which patients no longer received study medication, but continued to track headache information and received safety assessments. Patients who discontinued early from the treatment period could enter the post-treatment phase.

\section{Statistical analysis}

Safety and effectiveness analyses were conducted on an intent-to-treat (ITT) basis, which included all randomized patients who received at least one dose of study drug. Change from baseline included only those patients who had a baseline and at least one post-baseline assessment.

Continuous variables without repeated measures were analyzed as change from baseline to the last observation carried forward (LOCF) endpoint. Continuous safety and efficacy variables with repeated measures were analyzed using mixed-model repeated measures (MMRM), which included the fixed categorical effects of treatment, 
treatment-by-visit interaction, visit, as well as the continuous fixed covariates of baseline and baseline-by-visit interaction. In addition, pooled investigative site was also included in the efficacy analyses.

Categorical variables with repeated measures were summarized and analyzed in a similar manner as mean changes by a categorical, pseudo likelihood-based repeated measures analysis using a generalized linear mixed model (GLIMMIX) procedure in SAS (SAS Enterprise Guide 7.1). Categorical variables without repeated measures were analyzed by Fisher's exact test controlling for pooled investigative site.

The incidence of TE-ADA for each treatment group during the treatment period was summarized. Treatmentemergent ADA positive was defined as a 'not present' baseline ADA result and at least one 'present' post-baseline ADA result with a titer $\geq 1: 20$, or a 'present' baseline ADA result and a 'present' post-baseline ADA result with $a \geq 4$-fold increase in titer (i.e., baseline titer of 1:10 increasing to $\geq 1: 40$ post-baseline).

All statistical tests were conducted at a 2-sided alpha level of 0.05 . No adjustments for multiplicity were applied to any safety or effectiveness analyses.

\section{Results}

There were 341 patients screened for the study, of whom 270 patients enrolled. Overall completion rate for the treatment phase (Study Period 2) was $77.8 \%(N=210)$ (Fig. 1) with a total of 60 patients $(22.2 \%)$ who discontinued the treatment phase (Study Period 2). There were
236 patients (including some patients who discontinued treatment) who continued into the post-treatment phase (Study Period 3), and of these, 222 patients (94.1\%) completed all 4 months.

Baseline demographics and clinical characteristics were similar between the dose groups, except for a statistically significant difference between dose groups in the mean number of MHD and age (Table 1). Patients enrolled in this study were 42 years of age on average, majority were female $(83 \%)$ with a predominant diagnosis of episodic migraine (79\%), and an average of 10.6 monthly MHD. Patients were diagnosed with migraine an average of 20.7 years prior to study enrollment, and a majority of patients (63\%) reported prior use migraine preventive treatment, and $18.5 \%$ of the patients had one or more cardiovascular disease risk. The most common comorbid conditions ( $\geq 10 \%)$ were depression $(16.7 \%)$, seasonal allergy (16.7\%), drug hypersensitivity (15.6\%), back pain $(14.4 \%)$, insomnia $(14.4 \%)$, anxiety $(11.5 \%)$, and gastroesophageal reflux disease (10.4\%). The mean MIDAS total score of $50 \%$ indicated very severe headache-related disability [32] and function was restricted, as indicated by the average MSQ RF-R score of 48.

The mean duration of exposure to galcanezumab was 318.5 days and 310.3 days in the $120 \mathrm{mg}$ and $240 \mathrm{mg}$ dose groups, respectively. Of the patients who discontinued the treatment period early, significantly more patients in the galcanezumab $120 \mathrm{mg}$ dose group discontinued compared to the galcanezumab $240 \mathrm{mg}$ dose group $(P=.028)$. There were 4 patients who missed an injection at a home dosing

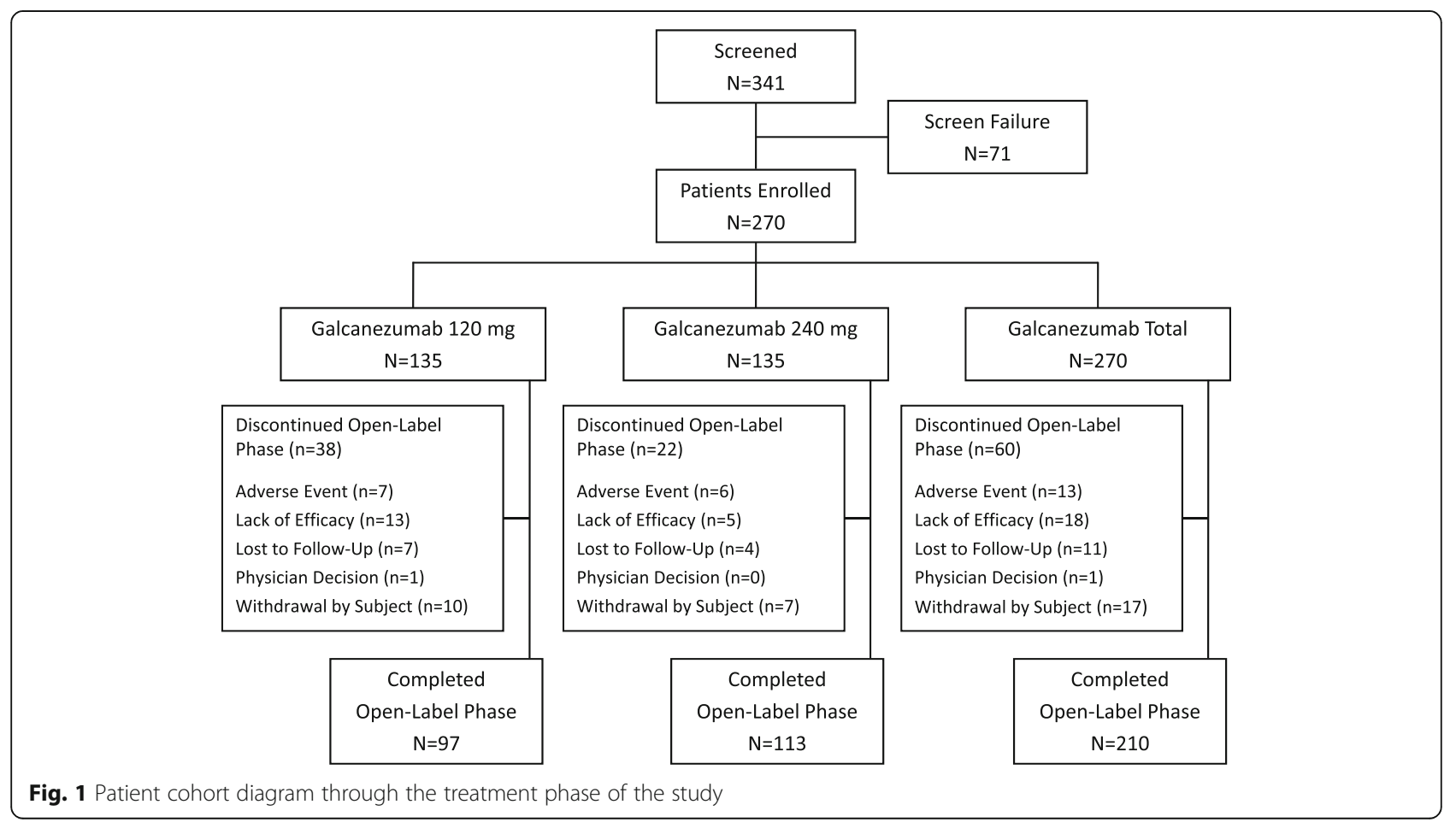


Table 1 Demographics and Clinical Characteristics

\begin{tabular}{|c|c|c|}
\hline & $\begin{array}{l}\text { Galcanezumab } \\
120 \mathrm{mg} \\
N=135\end{array}$ & $\begin{array}{l}\text { Galcanezumab } \\
240 \mathrm{mg} \\
N=135\end{array}$ \\
\hline Age in years, mean (SD) & $40.2(11.7)$ & $43.7(11.0)^{*}$ \\
\hline Female, $n(\%)$ & $110(81.5)$ & $113(83.7)$ \\
\hline Body mass index, $\mathrm{kg} / \mathrm{m}^{2}$, mean (SD) & $26.6(5.4)$ & $27.2(5.8)$ \\
\hline \multicolumn{3}{|l|}{ Race, $n(\%)$} \\
\hline Asian & $2(1.5)$ & 0 \\
\hline Black & $6(4.4)$ & $8(5.9)$ \\
\hline Multiple & $23(17.0)$ & $19(14.1)$ \\
\hline White & $103(76.3)$ & $108(80.0)$ \\
\hline Episodic migraine, $n$ (\%) & $109(80.7)$ & $104(77.0)$ \\
\hline $\begin{array}{l}\text { Cardiovascular Disease Risk } \\
\text { Group, } n(\%)^{\mathrm{a}}\end{array}$ & $22(17.1)$ & $28(19.9)$ \\
\hline Comorbid conditions, mean (SD) $)^{b}$ & $4.3(3.2)$ & $4.7(3.4)$ \\
\hline Depression & $19(14.1)$ & $26(19.3)$ \\
\hline Seasonal Allergy & $24(17.8)$ & $21(15.6)$ \\
\hline Drug hypersensitivity & $21(15.6)$ & $21(15.6)$ \\
\hline Back pain & $18(13.3)$ & $21(15.6)$ \\
\hline Insomnia & $19(14.1)$ & $20(14.8)$ \\
\hline Anxiety & $15(11.1)$ & $16(11.9)$ \\
\hline Gastroesophageal reflux disease & $12(8.9)$ & $16(11.9)$ \\
\hline Years since diagnosis, mean (SD) & $20.2(12.4)$ & $21.3(12.5)$ \\
\hline $\begin{array}{l}\text { Number of migraine headache } \\
\text { days, mean (SD) }\end{array}$ & $9.7(5.8)$ & $11.4(6.7)^{*}$ \\
\hline $\begin{array}{l}\text { Number of headache days, } \\
\text { mean (SD) }\end{array}$ & $5.0(6.8)$ & $6.1(8.1)$ \\
\hline $\begin{array}{l}\text { Number of days with acute migraine } \\
\text { medication use, mean (SD) }\end{array}$ & $9.8(6.6)$ & $10.9(7.2)$ \\
\hline Prior preventive treatment, $n(\%)$ & $81(60.0)$ & $88(65.2)$ \\
\hline $\begin{array}{l}\text { Patient Global Impression - } \\
\text { Severity, mean (SD) }\end{array}$ & $4.7(1.2)$ & $4.7(1.2)$ \\
\hline $\begin{array}{l}\text { Migraine Disability Assessment } \\
\text { total, mean (SD) }\end{array}$ & $45.8(42.1)$ & $54.0(61.2)$ \\
\hline $\begin{array}{l}\text { Migraine-Specific Questionnaire } \\
\text { Role Function-Restrictive domain } \\
\text { score, mean (SD) }\end{array}$ & $47.4(19.2)$ & 47.7 (18.4) \\
\hline
\end{tabular}

$S D$ standard deviation

${ }^{a}$ Patients with a history or pre-existing condition listed in any of the following MedDRA Standardized Queries: Ischaemic Heart Disease, Hypertension, Cardiac Failure, Cardiomyopathy, Ischaemic CNS Vascular Conditions, Dyslipidaemia, Hyperglycaemia/New Onset Diabetes Mellitus

${ }^{\mathrm{b}}$ Most common comorbid conditions $(\geq 10 \%)$ are reported. ${ }^{*} P<.05$

visit, but they did complete the treatment phase, and the mean treatment compliance in this study was 95.8 and $96.9 \%$ in the galcanezumab $120 \mathrm{mg}$ and $240 \mathrm{mg}$ dose groups, respectively. There was no between-dose group difference in the percentage of patients who discontinued due to an adverse event (AE) (4.7\% vs. 5.0\% for galcanezumab $120 \mathrm{mg}$ vs. $240 \mathrm{mg}$, respectively). In the galcanezumab $120 \mathrm{mg}$ dose group, 2 patients discontinued due to injection site reaction, and 1 patient each discontinued due to injection site erythema, lethargy, migraine, and suicidal ideation. In the galcanezumab $240 \mathrm{mg}$ dose group, 2 patients discontinued due to injection site reaction, and 1 patient each discontinued due to non-cardiac chest pain, paranoia, rash, tongue discomfort, and vertigo.

All of the 5 patients who discontinued due to an injection site-related TEAE had previous AEs at the injection site prior to discontinuation. Of these 5 patients, 4 patients discontinued after 6 or more self-administration dosing visits. One patient who had a severe injection site reaction discontinued after the tenth dosing visit due to progressive swelling around the site of the injection, with rash and pain that progressed from the previous injection that lasted a few days.

Ten patients reported SAEs, with 3 patients receiving galcanezumab $120 \mathrm{mg}$ and 7 patients receiving galcanezumab $240 \mathrm{mg}$. Lumbar radiculopathy, migraine, and osteoarthritis occurred in the galcanezumab $120 \mathrm{mg}$ dose group, while uterine leiomyoma embolization, cholecystitis, diverticulum intestinal, intervertebral disc protrusion, non-cardiac chest pain, pain in extremity and pneumonia occurred in the $240 \mathrm{mg}$ dose group. The events of non-cardiac chest pain and migraine led to discontinuation. None of these events was reported by the study investigator to be associated with galcanezumab treatment.

Treatment-emergent AEs that occurred with $\geq 5 \%$ frequency in either dose group are summarized in Table 2.

Table 2 Treatment-emergent adverse events with a $\geq 5 \%$ frequency of occurrence in either galcanezumab dose group

\begin{tabular}{|c|c|c|}
\hline Event & $\begin{array}{l}\text { Galcanezumab } \\
120 \mathrm{mg} \\
N=129 \\
n(\%)\end{array}$ & $\begin{array}{l}\text { Galcanezumab } \\
240 \mathrm{mg} \\
N=141 \\
n(\%)\end{array}$ \\
\hline Patient with $\geq 1 \mathrm{TEAE}$ & $106(82.2)$ & $121(85.8)$ \\
\hline Injection site pain & $22(17.1)$ & $28(19.9)$ \\
\hline Nasopharyngitis & $23(17.8)$ & $18(12.8)$ \\
\hline Upper respiratory tract infection & $9(7.0)$ & $21(14.9)$ \\
\hline Injection site reaction & $15(11.6)$ & $13(9.2)$ \\
\hline Back pain & $12(9.3)$ & $15(10.6)$ \\
\hline Sinusitis & $14(10.9)$ & $13(9.2)$ \\
\hline Nausea & $10(7.8)$ & $9(6.4)$ \\
\hline Injections site erythema & $9(7.0)$ & $9(6.4)$ \\
\hline Arthralgia & $8(6.2)$ & $8(5.7)$ \\
\hline Influenza & $8(6.2)$ & $8(5.7)$ \\
\hline Dizziness & $5(3.9)$ & $9(6.4)$ \\
\hline Injection site bruising & $5(3.9)$ & $8(5.7)$ \\
\hline Myalgia & $8(6.2)$ & $3(2.1)$ \\
\hline Weight increased & $7(5.4)$ & $4(2.8)$ \\
\hline
\end{tabular}

TEAE treatment-emergent adverse events

There were no statistically significant differences between dose groups in frequency of events 
There were no significant differences between dose groups in the frequency of any of these events; however, there was a higher percentage of upper respiratory tract infection events in the galcanezumab $240 \mathrm{mg}$ dose group (14.9\%) compared with $120 \mathrm{mg}$ group (7.0\%). Most of the TEAEs were reported as mild-to-moderate in severity and there were no deaths. Across both dose groups, the most common ( $\geq 10 \%$ frequency) events were injection site pain, nasopharyngitis, upper respiratory tract infection, injection site reaction, back pain, and sinusitis. In addition, injection site bruising, injection site hematoma, injection site pruritus, and injection site induration were reported in $>2 \%$ in both galcanezumab dose groups combined. There were no SAEs related to injection sites.

There were no clinically meaningful differences in laboratory parameters for either galcanezumab dose or between doses. No TEAE related to a laboratory analyte was reported as an SAE and none led to discontinuation. Elevated liver enzymes (as measured by alanine aminotransferase [ALT] or aspartate aminotransferase $[\mathrm{AST}] \geq 3 \mathrm{X}$ upper limit of normal [ULN]; or alkaline phosphatase [ALP] $\geq 2 \mathrm{X}$ ULN; or total bilirubin level [TBL] $\geq 2 \mathrm{X}$ ULN at any time) were reported as TEAEs by 4 patients (galcanezumab $120 \mathrm{mg} N=3$; galcanezumab $240 \mathrm{mg} N=1$ ) and these elevations were not persistent.

Systolic blood pressure mean changes from baseline to each month ranged from -1.45 to $+0.43 \mathrm{mmHg}$ in the galcanezumab $120 \mathrm{mg}$ group, and from -1.65 to $-0.27 \mathrm{mmHg}$ in the galcanezumab $240 \mathrm{mg}$ group. Diastolic blood pressure mean changes from baseline to each month ranged from -0.88 to $+0.87 \mathrm{mmHg}$ in the galcanezumab $120 \mathrm{mg}$ group, and from -0.81 to $+0.23 \mathrm{mmHg}$ in the galcanezumab $240 \mathrm{mg}$ group. There were statistically significant, but not clinically important, mean increases from baseline in pulse at Months 1, 2, 3, and 9 that were of similar magnitude across both dose groups (range: 2.0 to $3.7 \mathrm{bpm} ; P<.01$ ).

Few patients met criteria for treatment-emergent low systolic blood pressure, diastolic blood pressure, or pulse at any time (Table 3). There were no significant differences between galcanezumab dose groups in the frequencies of patients with treatment-emergent high systolic blood pressure or pulse at any time. There was a statistically significant increase in frequency of treatment-emergent high diastolic blood pressure in the galcanezumab $240 \mathrm{mg}$ dose group compared to the $120 \mathrm{mg}$ dose group $(P=.046)$. Four patients had a sustained elevation in diastolic blood pressure (2 patients in each dose group), of whom 2 patients ( 1 in each dose group) had sustained elevation in systolic blood pressure. However, these were not sustained beyond 2 consecutive visits. A review of the patient-level data revealed that the increased blood pressure findings were transient, isolated events and likely represented
Table 3 Treatment-emergent changes in blood pressure and pulse

\begin{tabular}{|c|c|c|c|c|}
\hline \multirow[t]{2}{*}{ Category } & \multicolumn{2}{|c|}{$\begin{array}{l}\text { Galcanezumab } \\
120 \text { mg }\end{array}$} & \multicolumn{2}{|c|}{$\begin{array}{l}\text { Galcanezumab } \\
240 \text { mg }\end{array}$} \\
\hline & $N$ & $n(\%)$ & $N$ & $n(\%)$ \\
\hline \multicolumn{5}{|l|}{ Elevated BP and pulse } \\
\hline $\begin{array}{l}\text { Sitting } S B P \geq 140 \mathrm{mmHg} \\
\text { and } \geq 20 \mathrm{mmHg} \text { increase } \\
\text { from baseline }\end{array}$ & 120 & $5(4.2)$ & 124 & $4(3.2)$ \\
\hline $\begin{array}{l}\text { Sitting } \mathrm{DBP} \geq 90 \mathrm{mmHg} \\
\text { and } \geq 10 \mathrm{mmHg} \text { increase } \\
\text { from baseline }\end{array}$ & 116 & $6(5.2)$ & 126 & $16(12.7)^{*}$ \\
\hline $\begin{array}{l}\text { Sitting pulse }>100 \mathrm{bpm} \\
\text { and } \geq 15 \mathrm{bpm} \text { increase from } \\
\text { baseline }\end{array}$ & 129 & $3(2.3)$ & 139 & $5(3.6)$ \\
\hline \multicolumn{5}{|c|}{ Sustained elevation at 2 consecutive visits } \\
\hline Sitting SBP & 119 & $1(0.8)$ & 119 & $1(0.8)$ \\
\hline Sitting DBP & 115 & $2(1.7)$ & 121 & $2(1.7)$ \\
\hline Sitting pulse & 128 & 0 & 133 & $3(2.3)$ \\
\hline \multicolumn{5}{|c|}{ Potentially clinically significant elevation at anytime } \\
\hline $\begin{array}{l}\text { Sitting SBP } \geq 180 \mathrm{mmHg} \\
\text { and } \geq 20 \mathrm{mmHg} \text { increase } \\
\text { from baseline }\end{array}$ & 129 & 0 & 139 & 0 \\
\hline $\begin{array}{l}\text { Sitting } D B P \geq 105 \mathrm{mmHg} \\
\text { and } \geq 15 \mathrm{mmHg} \text { increase } \\
\text { from baseline }\end{array}$ & 129 & $1(0.8)$ & 138 & $1(0.7)$ \\
\hline
\end{tabular}

$B P$ blood pressure, $D B P$ diastolic blood pressure, $S B P$ systolic blood pressure ${ }^{*} P<.05$

normal variation in blood pressure. Three of these patients did have a TEAE of hypertension. Two patients with high diastolic blood pressure (1 in each dose group) also met the criteria for potentially clinically significant elevations at any time (Table 3 ).

Across the 12 months of treatment, the mean changes from baseline to LOCF endpoint in weight were small for both galcanezumab dose groups $(\leq 1 \mathrm{~kg})$. Thirteen patients in the galcanezuamb $120 \mathrm{mg}$ dose group and 12 patients in the $240 \mathrm{mg}$ dose group had treatment-emergent weight loss $\geq 7 \%$; whereas, 17 patients in the $120 \mathrm{mg}$ dose group and 21 patients in the $240 \mathrm{mg}$ dose group had treatment-emergent weight gain $\geq 7 \%$. Given that the observed categorical weight changes occurred in both directions (weight loss and weight gain), there does not appear to be a clear impact of galcanezumab on weight.

There was a statistically significant mean increase from baseline in temperature of $0.2^{\circ} \mathrm{F}$ observed in each dose group at a single month (Month 1 for galcanezumab $120 \mathrm{mg}[P<.01]$, Month 9 for galcanezumab $240 \mathrm{mg}$ $[P<.05])$. A total of 10 patients overall experienced treatment emergent changes in body temperature. Five patients in the galcanezumab $120 \mathrm{mg}$ dose group and 4 patients in the $240 \mathrm{mg}$ dose group had low body temperatures $\left(<96^{\circ} \mathrm{F}\right.$ and a decrease of $\left.\geq 2^{\circ} \mathrm{F}\right)$, and 1 patient in the $120 \mathrm{mg}$ group had $\geq 101^{\circ} \mathrm{F}$ and an increase of $\geq 2^{\circ} \mathrm{F}$. Since 
these changes were temporary and small, they were not considered clinically meaningful.

The percentage of patients with treatment-emergent abnormal changes from baseline in ECG measures were $<5 \%$ (Table 4). However, neither galcanezumab dose groups resulted in ECG changes or serious cardiovascular events of concern. There were no discontinuations due to treatment-emergent ECG findings.

Four patients experienced treatment-emergent suicidal ideation based on assessment with the C-SSRS. One of these patients (galcanezumab $120 \mathrm{mg}$ dose) had a history of depression and was discontinued from the study after reporting suicidal ideation. The other 3 patients (galcanezumab $120 \mathrm{mg} N=2$; $240 \mathrm{mg} N=1$ ) had no prior lifetime history of suicidal ideation and continued in the study with no recurrence of suicidal ideation on the C-SSRS. None of the patients had emergence of suicidal behavior during treatment.

Anti-drug antibodies (ADA) were present at baseline in $8(6.3 \%)$ out of 128 patients evaluable for TE-ADA in the galcanezumab $120 \mathrm{mg}$ dose group, and in 12 out of $136(8.8 \%)$ patients in the $240 \mathrm{mg}$ dose group. Patients who developed TE-ADA included 16 (12.4\%) patients in the $120 \mathrm{mg}$ dose group and $10(7.3 \%)$ patients in the $240 \mathrm{mg}$ dose group. All of the patients who had TE-ADA also had neutralizing antibodies and the titers were generally low during this phase; the majority of the patients had maximum titers of 1:80 or below. Neutralizing ADA recognize the target-binding sites on galcanezumab and compete with binding to CGRP in vitro; an observable clinical effect requires sufficiently high titers of neutralizing ADA to effectively reduce the activity of galcanezumab in vivo.

Analysis of efficacy measures was a secondary objective in this study. Unless otherwise noted, the difference between galcanezumab $120 \mathrm{mg}$ and $240 \mathrm{mg}$ dose groups was not statistically significant on any efficacy measure.

Compared to baseline, the overall reduction in the number of monthly MHD was 5.6 (95\% CI: -6.3, - 5.0) and 6.5 (95\% CI: -7.1, - 5.8) for patients treated with galcanezumab $120 \mathrm{mg}$ and $240 \mathrm{mg}$, respectively (Table 5). Reduction in the mean monthly MHD was apparent as early as the first month and was sustained throughout the treatment period (Fig. 2).

The overall mean reduction from baseline in the number of monthly non-migraine headache days averaged over 12 months was 2.2 and 2.1 in the galcanezumab $120 \mathrm{mg}$ and $240 \mathrm{mg}$ dose groups, respectively (Table 5 ).

In both galcanezumab dose groups, there were statistically significant within-group reductions from baseline in the number of monthly MHD or headaches with acute medication use at each month $(P<.001)$. The overall mean reduction from baseline in number of monthly days with acute medication use for migraines or headaches was 5.1 in both dose groups (Table 5).

Response rate was defined as the mean percentage of patients meeting a pre-specified threshold in the reduction of the number of monthly MHD over Months 1 to 12. The overall response rates at each pre-specified threshold are summarized in Table 5. In each response category, there were more months where patients met that level of response in the galcanezumab $240 \mathrm{mg}$ dose group compared to the galcanezumab $120 \mathrm{mg}$ dose group. Of those patients who had at least a 50\% reduction from baseline in the number of monthly MHD, the percentage who continued to maintain at least a $40 \%$ reduction over 3 to 12 consecutive months is shown in Fig. 3. In the galcanezumab $120 \mathrm{mg}$ group, maintenance of response ranged from $48.5 \%$ ( $\geq 6$ consecutive months) to $24.2 \%$ (up to 12 consecutive months), and in the

Table 4 Change from baseline in electrocardiogram categorical measures

\begin{tabular}{|c|c|c|c|c|c|}
\hline \multirow[t]{2}{*}{ Category } & \multirow[t]{2}{*}{ Post Baseline } & \multicolumn{2}{|c|}{ Galcanezumab 120 mg } & \multicolumn{2}{|c|}{ Galcanezumab 240 mg } \\
\hline & & $N$ & $n(\%)$ & $N$ & $n(\%)$ \\
\hline \multirow[t]{2}{*}{ Heart rate } & $<50 \mathrm{bpm}$ and decrease $\geq 15$ & 117 & $1(0.85)$ & 131 & $1(0.76)$ \\
\hline & $>100 \mathrm{bpm}$ and increase $\geq 15$ & 119 & $1(0.84)$ & 131 & 0 \\
\hline \multirow[t]{2}{*}{ PR interval } & $<120 \mathrm{msec}$ & 117 & $3(2.56)$ & 127 & $1(0.79)$ \\
\hline & $\geq 220 \mathrm{msec}$ & 119 & 0 & 130 & 0 \\
\hline \multirow[t]{2}{*}{ QRS interval } & $<60 \mathrm{msec}$ & 120 & 0 & 131 & 0 \\
\hline & $\geq 120 \mathrm{msec}$ & 118 & 0 & 131 & $1(0.76)$ \\
\hline \multirow[t]{6}{*}{ QTCF } & $<330$ msec for males, < 340 msec for females & 118 & 0 & 130 & 0 \\
\hline & > 450 msec for males; > 470 msec for females & 118 & $2(1.69)$ & 130 & $1(0.77)$ \\
\hline & Potentially clinically significant: & & & & \\
\hline & $>500 \mathrm{msec}$ & 118 & 0 & 130 & 0 \\
\hline & Increase > 30 msec & 118 & $2(1.69)$ & 130 & $4(3.08)$ \\
\hline & Increase > 60 msec & 118 & 0 & 130 & 0 \\
\hline
\end{tabular}


Table 5 Overall change in monthly MHD, non-migraine headache days, and percentage reduction in monthly MHD

\begin{tabular}{lll}
\hline & Galcanezumab 120 mg & Galcanezumab 240 mg \\
& $N=135$ & -135 \\
\hline Overall change from baseline in number of monthly MHD, mean (SD) & $-5.6(0.34)$ & $-6.5(0.33)$ \\
Overall change from baseline in monthly non-migraine headache days, mean (SD) & $-2.2(0.3)$ & $-2.1(0.3)$ \\
Overall change from baseline in number of days with acute medication use, mean (SD) & $-5.1(0.4)$ & $-5.1(0.4)$ \\
Percentage of patients who had $\geq 30 \%$ reduction in MHD & $60.9 \%$ \\
Percentage of patients who had $\geq 50 \%$ reduction in MHD & $65.6 \%$ & $73.7 \%$ \\
Percentage of patients who had $\geq 75 \%$ reduction in MHD & $52.5 \%$ & $21.4 \%$ \\
\hline
\end{tabular}

$M H D$ migraine headache days, $S D$ standard deviation

$240 \mathrm{mg}$ group, maintenance of response ranged from $51.9 \%$ ( $\geq 6$ consecutive months) to $34.8 \%$ (up to 12 consecutive months).

Results from the Patient Global Impression of Improvement scale (PGI-I) is summarized in Table 6. In the galcanezumab $120 \mathrm{mg}$ dose group 90 patients completed the PGI-I, and $80 \%$ of patients reported that they were "much or very much better" and $4 \%$ reported "no change" or "a little worse". In the galcanezumab $240 \mathrm{mg}$ dose group 112 patients completed the PGI-I, and $85 \%$ of patients reported that they were "much or very much better" and $8 \%$ reported "no change" or "a little worse". There were no patients in either dose group who reported they were "much or very much worse".

Patients in both galcanezumab dose groups had improved functioning, as assessed by the MSQ RF-R domain, with increases from baseline in least squares (LS) mean scores of 31.6 and 33.4 for the $120 \mathrm{mg}$ and $240 \mathrm{mg}$ dose groups, respectively. Additionally, both galcanezumab dose groups had reduced headache-related disability, as assessed by the MIDAS total score, with LS mean reductions from baseline of -33.6 and -32.7 for the $120 \mathrm{mg}$ and $240 \mathrm{mg}$ dose groups, respectively.

\section{Discussion}

In this 12-month open-label study of once monthly subcutaneous injections of galcanezumab $120 \mathrm{mg}$ and $240 \mathrm{mg}$ as a preventive treatment for migraine, the safety and effectiveness profile observed was consistent with previous studies: two Phase 2 studies [22, 23], and two Phase 3 studies in patients with episodic migraine [24], and one Phase 3 study in patients with chronic migraine [33].

Tolerability to galcanezumab was demonstrated by the overall high study completion rate, which was $77.8 \%$ through all 12 months of treatment. In patients who completed the study, treatment compliance was $>95 \%$

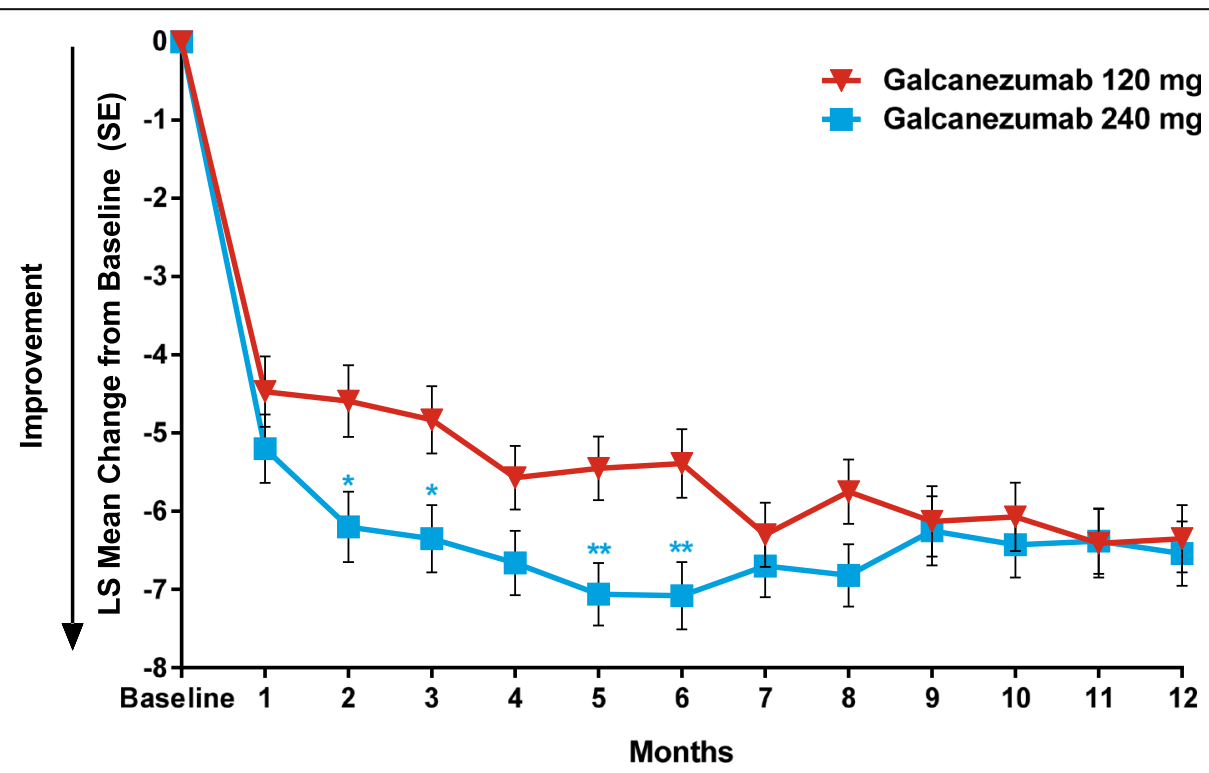

Fig. 2 Overall mean change from baseline in the number of monthly migraine headache days. ${ }^{*} P<.05 ;{ }^{*} P<.01$. Overall least squares (LS) mean change from baseline in the number of migraine headache days for patients who were treated with monthly open-label injections of galcanezumab $120 \mathrm{mg}$ or $240 \mathrm{mg}$ 


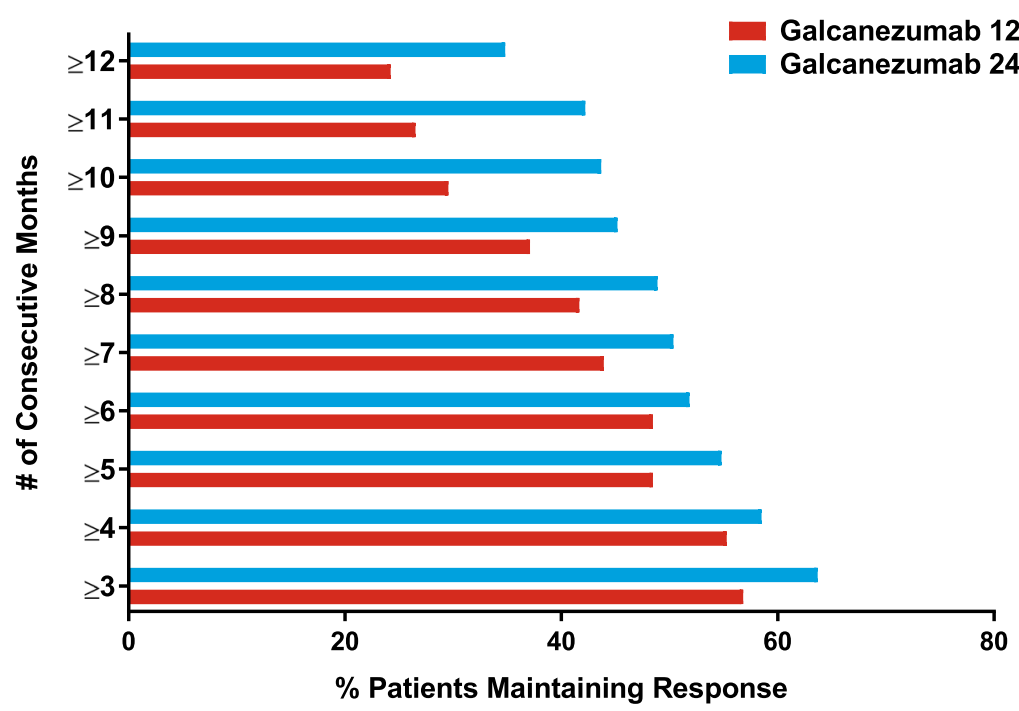

Fig. 3 Maintenance of response. Percentage of patients treated with monthly injections of galcanezumab $120 \mathrm{mg}$ or $240 \mathrm{mg}$, who had at least $50 \%$ or greater reduction from baseline in migraine headache days and maintained at least 40\% reduction over 3 to 12 consecutive months

and included at least half of the study visits being self-administered injections at home. Furthermore, the percentage of discontinuations due to AEs was low $(<5 \%$ combined doses), and few SAEs occurred $(<4 \%$ combined doses, and none considered related to treatment). This is in contrast to long-term treatment with topiramate, which is currently the most prescribed preventive migraine medication, which showed higher rates of study discontinuation and discontinuation due to adverse events [34, 35].

In this study, where patients or caregivers administered subcutaneous injections of galcanezumab, AEs of particular interest were those associated with the injection site. Approximately one-third of the patients experienced an injection site $\mathrm{AE}$, the reason for which 5 patients discontinued. Most of the TEAEs related to injection sites were mild or moderate in severity and occurred on the day of injection, and the majority were resolved by the next day. Of the 5 patients who discontinued due to an injection site $\mathrm{AE}, 4$ did so after multiple self-administrations. None of the TEAEs appeared to be different between the doses with the exception of the reported $\mathrm{AE}$ of upper respiratory tract infection. However, the cluster of events under upper respiratory infections show a similar incidence between the galcanezumab $120 \mathrm{mg}$ dose group (35.7\%) and the $240 \mathrm{mg}$ dose group (37.6\%). In addition, safety data from the Phase 3, double-blind, placebo-controlled studies for all three treatment groups (galcanezumab $120 \mathrm{mg}$, galcanezumab $240 \mathrm{mg}$, and placebo) showed a similar incidence of the $\mathrm{AE}$ of the upper respiratory tract infection [36].

Table 6 Improvement in functioning and patient impression of illness improvement

\begin{tabular}{|c|c|c|c|c|}
\hline & \multicolumn{2}{|c|}{ Galcanezumab 120 mg } & \multicolumn{2}{|c|}{ Galcanezumab 240 mg } \\
\hline & N & Mean (SE) or \% & N & Mean (SE) or \% \\
\hline MSQ RF-R, mean increase (improvement) & 130 & $31.6(1.2)$ & 135 & $33.4(1.2)$ \\
\hline MIDAS total, mean decrease (improvement) & 124 & $-33.6(2.1)$ & 130 & $-32.7(2.0)$ \\
\hline Patient Global Impression - IIIness Improvement at Month 12 & 90 & - & 112 & - \\
\hline Very much better & & $52.2 \%$ & & $52.7 \%$ \\
\hline Much better & & $27.8 \%$ & & $32.1 \%$ \\
\hline A little better & & $15.6 \%$ & & $7.1 \%$ \\
\hline No change & & $3.3 \%$ & & $7.1 \%$ \\
\hline A little worse & & $1.1 \%$ & & $0.9 \%$ \\
\hline Much worse & & $0 \%$ & & $0 \%$ \\
\hline Very much worse & & $0 \%$ & & $0 \%$ \\
\hline
\end{tabular}

MIDAS Migraine Disability Assessment, MSQ RF-R Migraine-Specific Questionnaire Role Function - Restrictive, SE standard error 
The safety of galcanezumab was supported by generally temporary and minimal changes from baseline in laboratory values, vital signs, ECG parameters, and weight. There were no clinically meaningful differences in laboratory parameters between the galcanezumab doses, based on mean changes from baseline to endpoint, as well as treatment-emergent changes (i.e., treatment-emergent abnormal, low, or high). These findings are supported by safety analyses performed with data pooled from two 6-month and one 3-month, Phase 3, double-blind, placebo-controlled studies [36].

Migraine may be associated with increased risk of suicidal ideation or behavior as reported by several studies $[8,9,37]$. In the current study, nearly $17 \%$ of the patients had comorbid depression, but treatment-emergent suicidal behavior was not reported. Four patients reported suicidal ideation as assessed by the C-SSRS. Three of these patients did not have a history of depression, but had a one-time incidence of treatment-emergent suicidal ideation as assessed by the C-SSRS, and all 3 patients continued in the study. One patient discontinued from treatment due to treatment-emergent suicidal ideation.

Immunogenicity is an important topic in therapies using monoclonal antibodies. Of particular interest is the development of ADA and their relevance in contributing to possible allergic drug reactions, neutralization of therapy (possibly reducing efficacy), and potential association with AEs. In this study, there were 26 patients who had TE-ADAs. Of these, only four patients reported one or more hypersensitivity events (specifically, rash and puritis) during the treatment phase and these events were mild-to-moderate in severity and all were resolved by the end of the treatment phase. Future analyses based on integrated safety and efficacy summaries across galcanezumab studies will allow for larger samples sizes, and potentially provide a better understanding of immunogenicity.

Effectiveness of treatment with galcanezumab was demonstrated by both doses on multiple migraine-relevant outcome measures over 12 months of treatment including: reduction in the number of monthly MHD; reduction in the number of days having a non-migraine headache; response rates; maintenance of response; and reduction in the frequency of acute medication use. The findings for the reduction in the number of monthly MHDs and response rates at the 50, 75, and $100 \%$ are consistent with findings reported by Ashina et al. 2017 in a 1-year open-label extension study of erenumab, a monoclonal antibody that blocks the CGRP receptor [38]. In addition, over $80 \%$ of the patients reported a disease improvement as measured by PGI-I to be "much better" or "very much better". Also, functioning was greatly improved, with changes from baseline in MSQ RF-R scores being three-fold greater than the within-group minimally important difference of 10.9 that has been determined for this domain [39]. In addition, headache-related disability was reduced from very severe to moderate.

This study is limited by the relatively small sample size, which precludes detection of any rare AE that may occur with long-term galcanezumab treatment. Patients with recent or serious cardiovascular conditions were excluded from participating in galcanezumab clinical studies, therefore caution should be used when treating these patients. In addition, there are limited data from the use of galcanezumab in pregnant women as they were excluded from participating in the galcanezumab studies. Interpretation of the effectiveness outcomes is limited by the open-label study design without comparison to placebo or another active treatment, and while the daily diaries collected the same information (migraine headache, headache, or use of acute medications), the use of a paper diary is a limitation of the study since an electronic diary can provide monitoring of daily entry and minimize recall bias. Nevertheless, the effectiveness results are similar to those of the more rigidly controlled Phase 3 studies. Lastly, in this study, the majority of the patients met criteria for episodic migraine and further assessment of the patients with episodic compared to chronic migraine will be explored in a future publication.

\section{Conclusion}

In summary, there were no new safety findings identified during 12 months of treatment with galcanezumab; favorable tolerability was evidenced by low discontinuation rates due to AEs, and TEAEs were transient and predominantly rated as mild or moderate in severity. Furthermore, there were no meaningful differences between galcanezumab doses with respect to measures of safety and tolerability. Although the study design was uncontrolled and open-label, the totality of migraine headache reduction along with improvement in functioning and disability, are considered to be clinically meaningful [39]. Results from this study confirm the long-term effectiveness of galcanezumab in patients with migraine.

\footnotetext{
Abbreviations

AEs: Adverse events; ALP: Alkaline phosphatase; ALT: Alanine aminotransferase; AST: Aspartate aminotransferase; BP: Blood pressure; bpm: Beats per minute; CGRP: Calcitonin gene-related peptide; C-SSRS: Columbia Suicide Severity Rating Scale; DBP: Diastolic blood pressure; ECGs: Electrocardiograms; GLIMMIX: Generalized linear mixed model; ICHD: International Classification of Headache Disorders; IHS: International Headache Society; ITT: Intent-to-treat; LOCF: Last observation carried forward; LS: Least squares; MHD: Migraine headache days; MIDAS: Migraine Disability Assessment; MMRM: Mixed-model repeated measures; MSQ RF-R: Migraine-Specific Quality of Life questionnaire Role Function - Restrictive; PGI-I: Patient Global Impression of Improvement; PR: Pulse rate; QTCF: QT interval adjusted for heart rate using Fridericia's correction; SAEs: Serious adverse events; SBP: Systolic blood pressure; SD: Standard deviation; SE: Standard error; TBL: Total bilirubin level; TE-ADA: Treatment-emergent anti-drug antibodies; TEAEs: Treatment-emergent adverse events; ULN: Upper limit of normal
} 


\section{Acknowledgements}

The authors would like to thank the patients who participated in this trial and the galcanezumab study team. We also thank Jonna Ahl, PhD and Vladimir Skljarevski, MD for their reviews and contributions to this disclosure. The authors especially thank the following study investigators: Michel Vandenheede, MD (Clinique St. Joseph, Liege, Belgium); Annelies Van Dycke, MD (Algemeen Ziekenhuis St Jan Brugge, Brugge, Belgium); Jan Versijpt, MD (Universitair Ziekenhuis Brussel, Brussel, Belgium); Ginette Girard, MD (DIEX Recherche Sherbrooke, Inc., Quebec, Canada); Marek Gawel, MD (Stroyan Research, Ontario, Canada); Farnaz Amoozegar, MD (University of Calgary, Alberta, Canada); Christelle Creác'h, MD (CHU St Etienne Hôpital Nord, Saint Etienne Cedex 2, France); Anne Donnet, MD (Hôpital de la Timone, Marseille Cedex 5, France); Michel Lanteri-Minet, MD (Hôpital de Cimiez, Nice, France); Caroline Roos, MD (Hôpital Lariboisiere, Paris Cedex 10, France); Judit Afra, MD (Orszagos Idegtudomanyi Intezet, Budapest, Hungary); Attila Csanyi, MD (Petz Aladar Megyei Oktato Korhaz, Gyor-Moson-Sopron, Hungary); Csaba Ertsey, MD (SE Neurologiai Klinika, Budapest, Hungary); Maria Satori, MD (Valeomed Kft., Komarom-Esztergom, Hungary); Brian Averell, DO (September 2015 - April 2016) (Wilmington Health Associates, Wilmington, NC, USA); Timothy James Oster, MD (April 2016- June 2016) (Wilmington Health Associates, Wilmington, NC, USA); Mesha McKinney Chadwick, MD (June 2016 - present) (Wilmington Health Associates, Wilmington, NC, USA); Jo H. Jaeger Bonner, MD (Mercy Health Research, St. Louis, MO, USA); John Burch, MD (Blue Ridge Research Center, Roanoke, VA, USA); Erin G. Doty, MD (Jacksonville Center for Clinical Research; Jacksonville, FL, USA); Corey Ericksen, DO (Ericksen Research and Development, Clinton, UT, USA); Shivkumar Hatti, MD (Suburban Research Associates, Media, PA, USA); David B. Kudrow, MD (California Medical Clinic for Headache, Santa Monica, CA, USA); Paula J. Lane, MD (Albuquerque Neuroscience, Inc., Albuquerque, NM, USA); Thomas G. Ledbetter, MD (ClinPoint Trials, LLC, Waxahachie, TX, USA); Hanid Audish, DO (Encompass Clinical Research, Spring Valley, CA, USA); Peter McAllister, MD (New England Institute for Clinical Research, Stamford, CT, USA); Harvey D. Schwartz, MD (Infinity Clinical Research, LLC, Hollywoood, FL, USA); Randal Lee Von Seggern, PharmD (PharmQuest, Greensboro, NC, USA); Elisabeth A. Barranco-Santana, MD (Ponce School of Medicine CAIMED Center, Ponce, Puerto Rico).

\section{Funding}

This study was sponsored by Eli Lilly and Company. Eli Lilly and Company designed the study, collected, analyzed, and interpreted the data as well as drafted the manuscript.

\section{Availability of data and materials}

The datasets used and/or analysed during the current study are available from the corresponding author on reasonable request.

\begin{abstract}
Authors' contributions
AC participated in the analyses and interpretation of data. DK participated in the data acquisition and interpretation of the data. SW participated in the study design and performing the statistical analyses. RS participated in the statistical analyses, interpretation of data, and drafting the manuscript. AVD and KJS participated in the interpretation of data. VLS participated in the study design, data acquisition, interpretation of the data, and drafting the manuscript. All authors have revised the manuscript critically for important content and approved the final manuscript.
\end{abstract}

\section{Ethics approval and consent to participate}

This study was reviewed and approved by appropriate institutional review boards and was conducted according to Good Clinical Practice and the Declaration of Helsinki. The ethical review boards included: Commissie Medische Ethiek Universitair Ziekenhuis (Institutes: Clinique St. Joseph, Algemeen Ziekenhuis St Jan Brugge, Universitair Ziekenhuis Brussel; Belgium), IRB Services (Institutes: DIEX Recherche Sherbrooke, Inc., Stroyan Research; Canada), Conjoint Medical Ethics Committee (Institute: University of Calgary, Canada), CPP Sud Mediterannée V (Institutes: CHU St Etienne Hôpital Nord, Hôpital de la Timone, Hôpital de Cimiez, Hôpital Lariboisiere; France), Egeszsegugyi Tudomanyos Tanacs (Institutes: Orszagos Idegtudomanyi Intezet, Petz Aladar Megyei Oktato Korhaz, SE Neurologiai Klinika, Valeomed Kft; Hungary), Quorum Review, Inc. (Institutes: Wilmington Health Associates, Mercy Health Research, Blue Ridge Research Center, Jacksonville Center for Clinical Research, Ericksen Research and Development, Suburban Research
Associates, California Medical Clinic for Headache, Albuquerque Neuroscience, Inc., ClinPoint Trials, LLC, Encompass Clinical Research, New England Institute for Clinical Research, Infinity Clinical Research, LLC, PharmQuest, Ponce School of Medicine CAIMED Center; USA).Patients provided written informed consent before initiating study procedures. The ethics committee approval covers all the sites in each country at the national level.

\section{Consent for publication}

Not applicable.

\section{Competing interests}

AC, SW, KJS, and VLS are full-time employees and minor shareholders of Eli Lilly and Company or one of its affiliates. RS was a full-time employee of Eli Lilly and Company at the time the manuscript was submitted. DK has received consultant fees from Eli Lilly, Amgen, Novartis and Alder and has received research support from Eli Lilly, Amgen, Alder, Teva, Allergan, Biohaven, CoLucid, VM Biopharma, and Roche-Genentech. AVD has received speaker fees from UCB, GSK, and Pfizer.

\section{Publisher's Note}

Springer Nature remains neutral with regard to jurisdictional claims in published maps and institutional affiliations.

\section{Author details}

${ }^{1}$ Eli Lilly Italia, Sesto Fiorentino, Italy. ${ }^{2}$ California Medical Clinic for Headache, Santa Monica, CA, USA. ${ }^{3}$ UCLA David Geffen School of Medicine, Los Angeles, CA, USA. ${ }^{4}$ Eli Lilly and Company Corporate Center, Indianapolis, IN 46285, USA. ${ }^{5}$ Neurology Department, AZ Sint-Jan Brugge, Brugge, Belgium.

Received: 28 February 2018 Accepted: 31 October 2018

Published online: 09 November 2018

\section{References}

1. GBD 2015 Disease and Injury Incidence and Prevalence Collaborators. Global, regional, and national incidence, prevalence, and years lived with disability for 310 diseases and injuries, 1990-2015: a systematic analysis for the Global Burden of Disease Study 2015. Lancet. 2016;388:1545-602.

2. Lipton RB, Bigal ME, Diamond M, et al. Migraine prevalence, disease burden, and the need for preventive therapy. Neurology. 2007;68:343-9.

3. Buse DC, Rupnow MF, Lipton RB. Assessing and managing all aspects of migraine: migraine attacks, migraine-related functional impairment, common comorbidities, and quality of life. Mayo Clin Proc. 2009;84:422-35.

4. Von Korff M, Crane P, Lane M, et al. Chronic spinal pain and physical-mental comorbidity in the United States: results from the national comorbidity survey replication. Pain. 2005:113:331-9.

5. Ifergane G, Buskila D, Simiseshvely N, Zeev K, Cohen H. Prevalence of fibromyalgia syndrome in migraine patients. Cephalalgia. 2006:26:451-6.

6. Hagen K, Einarsen C, Zwart JA, Svebak S, Bovim G. The co-occurrence of headache and musculoskeletal symptoms amongst 51050 adults in Norway. Eur J Neurol. 2002;9:527-33.

7. Sacco S, Kurth T. Migraine and the risk for stroke and cardiovascular disease. Curr Cardiol Rep. 2014;16:524.

8. Breslau N, Schultz L, Lipton R, Peterson E, Welch KM. Migraine headaches and suicide attempt. Headache. 2012;52:723-31.

9. Ilgen MA, Kleinberg F, Ignacio RV, et al. Noncancer pain conditions and risk of suicide. JAMA Psychiatry. 2013;70:692-7.

10. Evers S, Áfra J, Frese A, et al. EFNS guideline on the drug treatment of migraine - revised report of an EFNS task force. Eur J Neurol. 2009:16:968-81.

11. Silberstein SD and the US Headache Consortium. Practice parameter: evidence-based guidelines for migraine headache (an evidence-based review). Neurology. 2000;55:754-62.

12. Canadian Headache Society Guideline for Migraine Prophylaxis. A Peerreviewed supplement to The Canadian Journal of Neurological Sciences. Can J Neurol Sci. 2012;39 Suppl 2:S1-2.

13. Diamond S, Bigal ME, Silberstein S, et al. Patterns of diagnosis and acute and preventive treatment for migraine in the United States: results from the American migraine prevalence and prevention study. Headache. 2007:47:355-63.

14. Silberstein SD. Topiramate in migraine prevention: a 2016 perspective. Headache. 2017:57:165-78.

15. Dodick DW. Migraine. Lancet. 2018;391:1315-30. 
16. Silberstein SD, Holland S, Freitag F, et al. Evidence-based guideline update: pharmacologic treatment for episodic migraine prevention in adults. Report of the quality standards Subcommittee of the American Academy of neurology and the American headache society. Neurology. 2012;78:1337-45.

17. Steiner TJ, Paemeleire $K$, Jensen $R$, et al. European principles of management of common headache disorders in primary care. J Headache Pain. 2007;8(Suppl 1):S3-47

18. VanderPluym J, Evans RW, Starling AJ. Long-term use and safety of migraine preventive medications. Headache. 2016;56:1335-43.

19. Goadsby PJ, Edvinsson L, Ekman R. Vasoactive peptide release in the extracerebral circulation of humans during migraine headache. Ann Neurol. 1990;28:183-7.

20. Goadsby PJ, Edvinsson L. The trigeminovascular system and migraine: studies characterizing cerebrovascular and neuropeptide changes seen in humans and cats. Ann Neurol. 1993;33:48-56.

21. Vermeersch S, Benschop RJ, Van Hecken A, et al. Translational pharmacodynamics of calcitonin gene-related peptide monoclonal antibody LY2951742 in a capsaicin-induced dermal blood flow model. J Pharmacol Exp Ther. 2015;354:350-7.

22. Dodick DW, Goadsby PJ, Spierings ELH, et al. Safety and efficacy of LY2951742, a monoclonal antibody to calcitonin gene-related peptide, for the prevention of migraine: a phase 2, randomised, double-blind, placebocontrolled study. Lancet Neurol. 2014;13:885-92.

23. Skljarevski $V$, Oakes TM, Zhang Q, et al. Effect of different doses of galcanezumab vs placebo for episodic migraine prevention: a randomized clinical trial. JAMA Neurol. 2018;75:187-93.

24. Skljarevski V, Stauffer VL, Zhang Q, et al. Phase 3 Studies (EVOLVE-1 \& EVOLVE-2) of Galcanezumab in Episodic Migraine: Results of 6-Month Treatment Phase. Cephalalgia. 2017;37 Suppl 1:339.

25. Headache Classification Committee of the International Headache Society (IHS). ICHD-3 beta. The International Classification of Headache Disorders, 3rd edition (beta version). Cephalalgia. 2013;33:629-808.

26. Posner K, Brown GK, Stanley B, et al. The Columbia-suicide severity rating scale: initial validity and internal consistency findings from three multisite studies with adolescents and adults. Am J Psychiatry. 2011;168:1266-77.

27. Jhingran P, Osterhaus JT, Miller DW, Lee JT, Kirchdoerfer L. Development and validation of the migraine-specific quality of life questionnaire. Headache. 1998;38:295-302.

28. Stewart WF, Lipton RB, Kolodner K, Liberman J, Sawyer J. Reliability of the migraine disability assessment score in a population-based sample of headache sufferers. Cephalalgia. 1999;19:107-14.

29. Stewart WF, Lipton RB, Dowson AJ, Sawyer J. Development and testing of the migraine disability assessment (MIDAS) questionnaire to assess headache-related disability. Neurology. 2001;56(Suppl 1):S20-8.

30. Guy W. ECDEU assessment manual for psychopharmacology. Rockville: National Institute of Mental Health, Psychopharmacology Research Branch. Revised 1976. p 217 -222. https://archive.org/details/ ecdeuassessmentm1933guyw. Accessed 11 May 2018

31. Rendas-Baum R, Bloudek LM, Maglinte GA, Varon SF. The psychometric properties of the migraine-specific quality of life questionnaire version 2.1 (MSQ) in chronic migraine patients. Qual Life Res. 2013;22:1123-33.

32. Lipton RB, Stewart WF, Sawyer J, Edmeads JG. Clinical utility of an instrument assessing migraine disability: the migraine disability assessment (MIDAS) questionnaire. Headache. 2001;41:854-61.

33. Detke HC, Wang S, Skljarevski V, et al. A Phase 3 Placebo-Controlled Study of Galcanezumab in Patients with Chronic Migraine: Results from the 3-month Double-Blind Treatment Phase of the REGAIN Study. Cephalalgia. 2017;37 Suppl 1:338

34. Malessa R, Gendolla A, Steinberg B, et al. Prevention of episodic migraine with topiramate: a prospective 24-week, open-label, flexible-dose clinical trial with optional 24 weeks follow-up in a community setting. Curr Med Res Opin. 2010;26:1119-29.

35. Nelles $G$, Schmitt L, Humbert T, et al. Prevention of episodic migraines with topiramate: results from a non-interventional study in a general practice setting. J Headache Pain. 2010;11:33-44.

36. Stauffer VL, Wang $S$, Bangs, $M$, et al. Phase-3 safety data from studies comparing galcanezumab and placebo in patients with episodic and chronic migraine. Eur J Neurol. 2018;25(Suppl. 2):298.
37. Friedman LE, Zhong QY, Gelaye B, Williams MA, Peterlin BL. Association between migraine and suicidal behaviors: a nationwide study in the USA. Headache. 2018;58:371-80.

38. Ashina M, Dodick D, Goadsby PJ, et al. Erenumab (AMG 334) in episodic migraine: interim analysis of an ongoing open-label study. Neurology. 2017; 89:1237-43.

39. Dodick DW, Turkel CC, DeGryse RE, et al. Assessing clinically meaningful treatment effects in controlled trials: chronic migraine as an example. J Pain. 2015;16:164-75.

\section{Ready to submit your research? Choose BMC and benefit from:}

- fast, convenient online submission

- thorough peer review by experienced researchers in your field

- rapid publication on acceptance

- support for research data, including large and complex data types

- gold Open Access which fosters wider collaboration and increased citations

- maximum visibility for your research: over $100 \mathrm{M}$ website views per year

At BMC, research is always in progress.

Learn more biomedcentral.com/submissions 